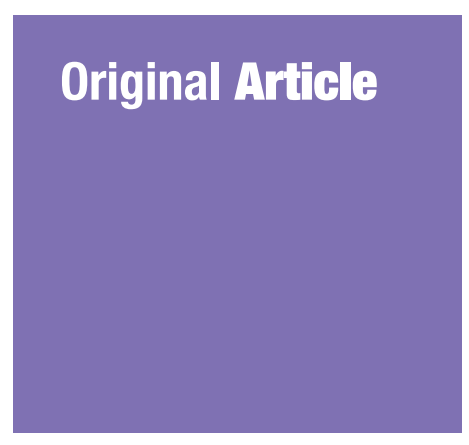

Submitted: 12 May 2021 Accepted: $16 \mathrm{Jul} 2021$ Online: 23 Feb 2022

\section{Antibiotic Prescribing Patterns for Patients with Pharyngitis in Malaysian Public Primary Care Clinics}

\author{
AbdulRahman MuthannA ${ }^{1,2}$, Siti Zulaikha ZAKARIAH ${ }^{1}$, Aneesa \\ Abdul RASHID ${ }^{3}$, Sazlina Shariff GHAZALI ${ }^{3}$, Rukman Awang \\ HAMAT $^{1}$, Maliza MAWARDI ${ }^{3}$, Hani Syahida SALIM ${ }^{3}$, Nurainul Hana \\ SHAMSUDDIN ${ }^{3}$
}
1 Department of Medical Microbiology, Faculty of Medicine and Health Sciences, Universiti Putra Malaysia, Selangor, Malaysia
2 Department of Biomedical Sciences, Faculty of Medicine and Health Sciences, Universiti Putra Malaysia, Selangor, Malaysia
3 Department of Family Medicine, Faculty of Medicine and Health Sciences, Universiti Putra Malaysia, Selangor, Malaysia

To cite this article: Muthanna AR, Zakariah SZ, Abdul Rashid A, Ghazali SS, Hamat RA, Mawardi M, Salim HS, Shamsuddin NH. Antibiotic prescribing patterns for patients with pharyngitis in Malaysian public primary care clinics. Malays J Med Sci. 2022;29(1):91-100. https://doi.org/10.21315/mjms2022.29.1.9

To link to this article: https://doi.org/10.21315/mjms2022.29.1.9

\begin{abstract}
Background: Over-prescription of antibiotics for upper respiratory tract infection (URTI) is a continuing problem in Malaysia, leading to increased antimicrobial resistance and unnecessary cost incurred for treatment. In a patient presenting with a sore throat, it is recommended to only prescribe antibiotics to group A streptococcus (GAS) pharyngitis confirmed by a throat culture, rapid antigen test or in patients with a Centor score of 4 .

Methods: This cross-sectional study assessed the proportion of antibiotics prescribed and antimicrobial susceptibility patterns of GAS pharyngitis in the Malaysian primary care setting. Two-hundred and fifteen adult patients presenting with sore throat were recruited in three primary care clinics. Demographic data and clinical information were collected and analysed. Centor scores were calculated according to the clinical information and throat swabs were collected from all participants for GAS identification.

Results: Only six throat swabs isolated GAS and indicated for antimicrobial treatment (2.8\%). However, 48 participants (22.3\%) were prescribed antibiotics out of which only four (8.3\%) patients with isolated GAS, including three (6.2\%) patients who clinically had a Centor score of 4 and one patient with a score of 3. Amoxicillin and erythromycin were the most commonly prescribed antibiotics (58.3\% and $25 \%$ of all antibiotics, respectively).

Conclusion: There is a high proportion of antibiotic prescriptions which were not indicated in patients with sore throat in this study. This may reflect a common practice of antibiotic overuse for sore throat in primary care settings in Malaysia. Concerted interventions to reduce the inappropriate prescribing of antibiotics are urgently needed.
\end{abstract}

Keywords: pharyngitis, primary care, antibiotics, prescription, inappropriate prescribing

\section{Introduction}

Upper respiratory tract infection (URTI) is the most common acute illness seen in primary care clinics globally. In 2015, the global incidence of URTI was over 17 billion (1). URTI in adults are mainly caused by a virus; only about $10 \%$ of incidences are bacterial, mainly caused by group A streptococci (GAS), which is the only indication for antimicrobial therapy (2). In GAS 
pharyngitis, oral penicillin $\mathrm{V}$ for 10 days or a single dose of parenteral penicillin $\mathrm{G}$ effectively reduces symptom duration by 1 day to 2 days, spread of the disease, and incidence of toxigenic and immunologic complications (3).

In general, antibiotics are safe and provide moderate clinical benefits in a minority of patients with pharyngitis (4). Whereas, antibiotics should be prescribed only for patients with GAS pharyngitis (2). However, previous studies have reported that there is an overprescription of antibiotics for URTI in general practice, where $73 \%$ of patients with pharyngitis were prescribed antibiotics $(5,6)$. In Malaysia, antibiotics are commonly prescribed by primary care providers and most frequently for respiratory tract infections (7).

Indiscriminate use of antibiotics has been identified as one of the major factors associated with the escalating rates of antimicrobial resistance (8). Also, it causes adverse effects (e.g. allergy or diarrhoea) and adds to the economic burden of the health care system worldwide (9).

GAS (Streptococcus pyogenes) and other beta-haemolytic streptococci are sensitive to penicillin and cephalosporin as well as rifampin and vancomycin (10, 11). However, some strains of the bacterium have been found to be resistant to macrolides, tetracycline and clindamycin (10). The present study determines the antibiotic prescribing rates and factors contributing to antibiotic prescription for adults with a sore throat in three primary care clinics in Malaysia. It extends to study the antimicrobial susceptibility patterns of betahaemolytic streptococci (groups A, B, C, F and G) that cause pharyngitis and aims to determine if the antibiotics chosen for these conditions are consistent with the local antibiotic guideline (12).

\section{Methods}

Using a cross-sectional study design, questionnaires containing demographic data, clinical information and treatment prescribed were administered and throat swabs were collected from $\geq 18$ years old patients who complain of a sore throat. Patients were recruited using simple convenience sampling in three health clinics in Selangor, Malaysia. Patients who treated with antibiotics within two weeks, pregnant, very ill or who were immunocompromised (except those with diabetes mellitus) were excluded.
The sample size was calculated using single proportion sampling (13), based on the previous prevalence of pharyngitis in Thailand (14), with consideration of an estimated 20\% incomplete data. The total sample size was 215 .

Researchers screened patients at the triage counter of the clinics. Patient information sheets were provided to eligible patients. After reviewing the information and agreeing to participate, the patient would be administered an informed consent form and the researchers completed the study questionnaire. The researchers then collected a throat swab and later verified and completed the remaining clinical information (diagnosis and prescription) in the questionnaire according to the medical records.

The throat swabs were then cultured to identify $\beta$-haemolytic streptococci. Each $\beta$-haemolytic streptococci isolates further tested to identify streptococcal groups A, B, C, F and G. Subsequently, antimicrobial susceptibility testing according to the Clinical and Laboratory Standards Institute (15), were performed to study antibiotic susceptibility patterns of the pathogen against the following antibiotics: penicillin $\mathrm{G}$, ampicillin, erythromycin, clindamycin, ofloxacin, cefepime, cefotaxime, ceftriaxone, tetracycline, linezolid and vancomycin.

\section{Data Analysis}

Continuous data were presented as means and standard deviations. Categorical variables were presented as whole numbers and percentages. The comparison of categorical variables was made using Pearson Chisquared and Fisher's exact tests as appropriate. A probability of $P<0.05$ was considered statistically significant.

\section{Results}

\section{Demographic Characteristics}

The total number of participants was 215 in the three clinics (response rate was 89.9\%). Twenty-two patients were ineligible (five were treated with antibiotics within less than 2 weeks, two pregnant women and 15 were aged less than 18 years old), and two patients refused to participate in the study. The mean age was 36.43 years old. The proportion of female participants $(57.7 \%)$ was slightly higher than male participants (42.3\%). The majority 
of participants were Malay (62.8\%) followed by Indian (30.2\%), Chinese (5.1\%) and others (1.9\%).

\section{Antibiotic Prescription Rate}

Antibiotics were prescribed in 48 (22.3\%) out of 215 participants. Table 1 shows the sociodemographic characteristics of patients prescribed antibiotics. More male patients were given antibiotics in the clinics compared with female patients. Antibiotics were mostly prescribed to patients aged 18 years old-28 years old and Malay patients. Chi-squared test and Fisher's exact test showed that there was a significant association between antibiotic prescription with ethnicity and smoking status $(P<0.05)$. Overall, cough and rhinorrhea are the most common clinical manifestations for antibiotics prescribed. Prescribed antibiotics were significantly associated with swollen anterior cervical lymph, tonsillar swelling or exudates pharyngitis/tonsillitis and non-GAS pharyngitis. Among 48 prescribed antibiotics, 3 (6.2 \%) with Centor score 4, 6 (12.5\%) with Centor score 2, 3 (6.3\%) with Centor score 3 and $36(75.0 \%)$ with Centor score $0-1$. The results show that the Centor score of $0-1$ and Centor score of 4 are associated with antibiotic prescription $(P<0.05)$.

Table 2 shows the distribution of the types of prescribed antibiotics. All of the prescribed antibiotics were in oral form. The most prescribed antibiotic was amoxicillin $500 m$ for seven days which was dispensed in 28 cases. Four out of six cases of laboratoryconfirmed GAS pharyngitis were treated with antibiotics. In contrast, one case was not treated with antibiotics and one case was referred to the hospital because of unspecified complications.

\section{Antimicrobial Susceptibility Patterns}

Beta-haemolytic streptococci were isolated from 80 (37.2\%) participants. Among the 80 isolates of the beta-haemolytic streptococci, GAS was positive in $6(2.8 \%)$ participants. All isolates were susceptible to penicillin G, ampicillin, ofloxacin, cefepime, cefotaxime, ceftriaxone, vancomycin and linezolid. However, $38.8 \%$ of beta-haemolytic streptococci (groups A, B, C, $\mathrm{F}$ and $\mathrm{G}$ ) found to be resistant to tetracycline, $5 \%$ resistant to clindamycin and erythromycin resistance was $11.3 \%$.

\section{Discussion}

In the present study, doctors in the three primary care clinics prescribed antibiotics to $48(22.3 \%)$ of the patients with a sore throat $(N=215)$.

From the total prescriptions in this study, 37 (77.1\%) were diagnosed with pharyngitis/ tonsilitis. This shows that antibiotic prescription is associated with pharyngitis/tonsilitis $(P<0.005)$. Interestingly, overall we found only six throat swab samples were laboratory confirmed GAS, while in terms of clinical characteristics based on the Centor scoring, only three patients (1.4\%) scored 4 and 8 patients (3.7\%) scored 3. Antibiotics are only indicated in a patient with sore throat if it is GAS or if they have a Centor score of 4 and judiciously if they score 3. In our study, all patients who scored 4 received antibiotics and had a positive culture for GAS. However, not all patients with laboratory confirmed GAS received antibiotics in which two had positive throat swab cultures and both had a Centor score of 3. This shows that in this study, a Centor score of 4 is associated with GAS $(P<0.05)$ and antibiotic prescription $(P=0.001)$. But in terms of prescribing habit, a diagnosis of pharyngitis/tonsilitis correlates with the decision to prescribe, although most of these cases do not fulfil the clinical criteria of GAS pharyngitis as we found 42 patients who were prescribed antibiotics $(87.5 \%)$ had a Centor score of $0-2$. Studies have shown with a sore throat only $8.3 \%$ (7) of them with GAS pharyngitis, which is the only indication for antibiotics therapy (8). Therefore, the over prescription rate in this study was $91.7 \%(9,10)$. For most patients with respiratory tract infection, antibiotic use is unnecessary and these results suggest that antibiotics were not clinically indicated, therefore overused in the three primary care clinics in Malaysia. Excessive or suboptimal use of medicine in general and antibiotics in particular, is a worldwide concern $(16,17)$.

The antibiotic prescription rate in this study was lower than the rate in a study at public primary care clinics which was carried out in Malaysia, where the antibiotic prescription rate was $34.1 \%$ among patients with a sore throat (18). It was comparable to a study conducted in Malaysia where $21.1 \%$ of antibiotics prescribed for upper respiratory tract infections (19). A study was done by Hicks et al. (20) in the United States of America has reported that the rate of prescribed antibiotics to adults with a sore 
Table 1. Characteristics of patients prescribed with antibiotics

\begin{tabular}{|c|c|c|}
\hline Variables & $\begin{array}{c}\text { Antibiotic prescribed }(n=48) \\
n(\%)\end{array}$ & $P$-value \\
\hline \multicolumn{3}{|l|}{ Age group (years old) } \\
\hline $18-28$ & $23(47.9)$ & $0.103^{c}$ \\
\hline $29-39$ & $15(31.2)$ & \\
\hline $40-50$ & $6(12.5)$ & \\
\hline $51-60$ & $3(6.3)$ & \\
\hline$\geq 61$ & $1(2.1)$ & \\
\hline \multicolumn{3}{|l|}{ Gender } \\
\hline Male & $25(52.1)$ & 0.121 \\
\hline Female & $23(47.9)$ & \\
\hline \multicolumn{3}{|l|}{ Ethnicity } \\
\hline Malay & $38(79.2)$ & $0.033^{\mathrm{c}^{*}}$ \\
\hline Indian & o (o.o) & \\
\hline Chinese & $10(20.8)$ & \\
\hline Others & o (o.o) & \\
\hline \multicolumn{3}{|l|}{ Smoking status } \\
\hline Smoker & $14(29.2)$ & $0.033^{*}$ \\
\hline Non-smoker & $34(70.8)$ & \\
\hline \multicolumn{3}{|l|}{ Clinical manifestations } \\
\hline Cough & $42(87.5)$ & $0.385^{\mathrm{c}}$ \\
\hline Rhinorrhea & $37(77.1)$ & 0.690 \\
\hline Swollen anterior cervical lymph & $18(37.5)$ & $0.008^{*}$ \\
\hline Fever $\geq 38^{\circ} \mathrm{C}$ & $6(12.5)$ & 0.088 \\
\hline Tonsillar swelling or exudates & $25(52.1)$ & $0.001^{*}$ \\
\hline Fever $\geq 37.5{ }^{\circ} \mathrm{C}$ & $9(18.8)$ & 0.181 \\
\hline \multicolumn{3}{|l|}{ Diagnosis } \\
\hline Pharyngitis/tonsillitis & $37(77.1)$ & $0.008^{*}$ \\
\hline URTI & $4(8.2)$ & 0.077 \\
\hline Coryza & $3(6.3)$ & 0.294 \\
\hline Pneumonia & o (o.o) & $1.000^{\mathrm{c}}$ \\
\hline Others & $4(8.4)$ & $0.015^{*}$ \\
\hline 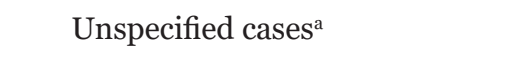 & $\mathrm{o}(0.0)$ & $<0.001^{\mathrm{c}^{*}}$ \\
\hline \multicolumn{3}{|l|}{ Throat swab results } \\
\hline GAS & $4(8.3)$ & $0.023^{\mathrm{c}^{*}}$ \\
\hline Non-GAS ${ }^{b}$ & $44(91.7)$ & \\
\hline \multicolumn{3}{|l|}{ Centor score } \\
\hline Score $0-1$ & $36(75.0)$ & $0.048^{*}$ \\
\hline Score 2 & $6(12.5)$ & 0.560 \\
\hline Score 3 & $3(6.3)$ & 0.294 \\
\hline Score 4 & $3(6.3)$ & $0.001^{\mathrm{c}^{*}}$ \\
\hline
\end{tabular}

Notes: ${ }^{\mathrm{a}}$ Either cases have not identified the diagnosis or have identified symptoms only; ${ }^{\mathrm{b}}$ Cases which were negative for GAS test; ${ }^{\mathrm{c}}$ Fisher's exact test; ${ }^{\text {" }} \mathrm{P}<0.05$ 
Table 2. Distribution of the types of prescribed antibiotics

\begin{tabular}{lc} 
Prescribed antibiotics & $n(\%)$ \\
Oral erythromycin (EES) 800 mg & $5(10.4)$ \\
Oral erythromycin (EES) 400 mg & $7(14.6)$ \\
Oral amoxicillin 500 mg & $28(58.3)$ \\
Oral amoxicillin $250 \mathrm{mg}$ & $1(2.1)$ \\
Oral co-amoxiclav 625 mg & $1(2.1)$ \\
Oral cefuroxime $125 \mathrm{mg}$ & $1(2.1)$ \\
Oral cephalexin 500 mg & $4(8.3)$ \\
Oral cloxacillin 500 mg & $1(2.1)$ \\
Total & $48(100)$ \\
\hline
\end{tabular}

throat was $73.7 \%$. However, another study about the variations of prescribed antibiotics in the European Union among adults with a sore throat has shown that the prescribed antibiotics rates were lower than this study in the Netherlands (8.9\%) and Sweden (13.5\%). In comparison, it was close to a study in Belgium (26.7\%) (21). Although the rate of the prescribed antibiotics in this study is lower than the rates in other studies but it exceeds the expected prevalence of GAS among adults.

In this study, the majority of prescribed antibiotics were amoxicillin and erythromycin. Oral amoxicillin $500 \mathrm{mg}$, oral co-amoxiclav $625 \mathrm{mg}$ and oral cephalexin $500 \mathrm{mg}$ were prescribed for the patients with GAS pharyngitis for 5 days -7 days by the physicians in the primary care clinics. Meanwhile, 44 patients diagnosed with non-GAS were treated with oral EES $800 \mathrm{mg}$, oral EES $400 \mathrm{mg}$, oral amoxicillin $500 \mathrm{mg}$, oral amoxicillin $250 \mathrm{mg}$, oral cefuroxime axetil $125 \mathrm{mg}$, oral cephalexin $500 \mathrm{mg}$ and oral cloxacillin $500 \mathrm{mg}$ for 5 days7 days. The National Antibiotic Guideline in Malaysia has recommended amoxicillin $500 \mathrm{mg}$ or phenoxymethylpenicillin $500 \mathrm{mg}$ for 10 days to treat pharyngitis that are caused by GAS; however, the alternative therapy is a single dose of benzathine penicillin, azithromycin $500 \mathrm{mg}$ for 5 days or clindamycin $300 \mathrm{mg}-450 \mathrm{mg}$ for 10 days to patients who allergic to penicillin (22). Other studies have shown that oral penicillin V for 10 days or a single dose of parenteral penicillin $G$ was the first line of antibiotics to treat GAS pharyngitis and it was reduced the duration of the symptom $(23,24)$. In addition, another study has reported that penicillin antibiotic treatment within 9 days was sufficient to prevent rheumatic fever (25). In contrast, other studies have proved that treatment of GAS pharyngitis by amoxicillin, erythromycin, oral cephalosporins and clindamycin for 7 days was sufficient to reduce the symptoms (26, 27). Therefore, this study has found that the physicians in the three clinics did not follow the National Antibiotic Guideline in Malaysia to prescribe antibiotics to adult patients with a sore throat.

In this study, among the 80 isolates of betahaemolytic streptococci (groups A, B, C, F and G) which collected from the throat of adults with a sore throat in the three primary care clinics, there were no strains resistant to penicillin, ampicillin, ofloxacin, cefepime, cefotaxime, ceftriaxone, linezolid and vancomycin and there were strains resistant to tetracycline, erythromycin and clindamycin. Penicillin or ampicillin is the first line of antibiotic which is recommended to treat GAS pharyngitis by international and local guidelines (28). The present study confirmed that the resistance to penicillin or ampicillin has not identified in betahaemolytic streptococcal (groups A, B, C, F and G) strains, thus far $(29,30)$, and even study in Sweden about penicillin tolerance in GAS has found five strains from cases cause treatment failures in pharyngitis seems doubtful (31). Beta-haemolytic streptococcal (groups A, B, C, $\mathrm{F}$ and $\mathrm{G}$ ) isolates were found to be susceptible to ofloxacin, cefepime, cefotaxime, ceftriaxone, linezolid and vancomycin. Previous studies have confirmed the results of this study, where the results obtained have shown the similar activity of ofloxacin, cefepime, cefotaxime, ceftriaxone, linezolid and vancomycin against beta-haemolytic streptococci (groups A, B, C, F and G) (32-34). However, a study comparing the susceptibility of clinical group A, B, C, F and $\mathrm{G}$ beta-haemolytic streptococcal isolates for 24 antimicrobial drugs found two group C streptococcal strains (1.9\%) to be resistant to ofloxacin (35). In addition, a study carried out among 177 patients with pharyngitis in Iraq has reported one group $\mathrm{F}$ streptococcal isolate to be resistant to vancomycin (36). However, Clinical and Laboratory Standards Institute (CLSI) documents have reported that the isolates with reduced susceptibility to vancomycin cannot be differentiated from susceptible isolates by disk diffusion test (15). Clindamycin and macrolides are available and are used as an alternative therapy to treat streptococcal pharyngitis for patients allergic 
to penicillin (37). This study had detected low level resistance to clindamycin and erythromycin where $5 \%$ of beta-haemolytic streptococci (groups A, B, C, F and G) isolates were resistant to clindamycin and $11.3 \%$ were resistant to erythromycin. This result correlates with a study in Northern Spain, which has reported a low rate of erythromycin and clindamycin resistance where the rate of erythromycin resistance was $9.3 \%$ and clindamycin resistance was $1.7 \%$ (38). Tetracycline is not recommended as a treatment for streptococcal pharyngitis but it is a broad spectrum antibiotic that can be used to treat a variety of bacterial infections, which means a high total level of consumption (39). The resistance to tetracycline has been widespread among beta-haemolytic streptococci (40). This study confirmed what other studies had reported about the high resistance of betahaemolytic streptococci (groups A, B, C, F and G) to tetracycline especially GAS and group B streptococci, where the resistance of betahaemolytic streptococci was $38.8 \%$ (35). As another study in Thailand has reported that $52 \%$ of beta-haemolytic streptococci were resistant to tetracycline (41). In addition, a high tetracycline resistance rate of beta-haemolytic streptococci (groups A, B, C, F and G) was reported in other studies performed in India (73\%), Germany (74.5\%) and France (88.1\%) (42-44). In contrast to this study, low levels of tetracycline resistance among beta-haemolytic streptococcal isolates were reported in Spain (7.3\%) and in Sweden $(1.3 \%)(45,46)$. In Japan, the resistance rate of beta-haemolytic streptococci (groups A, B, $\mathrm{C}, \mathrm{F}$ and $\mathrm{G})$ to tetracycline was declined from $61.2 \%$ in 1981 to $20 \%$ in 1990 (47). Therefore, tetracycline is not recommended as a treatment for streptococcal pharyngitis.

Erythromycin resistance rate for GAS in Malaysia remained constant between $4.3 \%$ and $5.7 \%$ over the past 5 years and between $0.8 \%$ and $2.2 \%$ for ampicillin. Whereas tetracycline resistance has been recorded to be between $55.6 \%$ and $58.4 \%$ in the same period $(11,12)$.

This study has some limitations, the definitions of pharyngitis, tonsillitis and URTI, which used in this study were intentionally broad because diagnoses were not necessarily accurately recorded in the medical record. The definition of pharyngitis, tonsillitis and URTI would have captured almost all 'true' URTI but may have included some patients presenting with undifferentiated cough, runny nose, sore throat, injected throat and enlarged tonsils that may have turned out not to be a URTI. In addition, this study was limited to three primary clinics only from one area.

\section{Conclusion}

This study has confirmed that antibiotics are frequently prescribed in the Malaysian primary care settings and antibiotic prescribing rates for URTI is high. Excessive and inappropriate antibiotic use in Malaysian primary care setting highlights the need for more concerted interventions targeting prescribers as well as the general public. Therefore, the antibiotic prescribing rates in Malaysia may still be a cause for concern as the high prescribing rate may cause increasing antibiotic resistance in the future. There is a need to develop educational materials and training programmes for health care physicians regarding the guidelines of antimicrobial prescribing, antibiotic resistance, clinical diagnosis, clinical scoring and the effects of unnecessary antibiotic prescription. Improvement strategies should focus on reducing inappropriate prescribing. Penicillin and ampicillin might serve as the preferred antibiotics to treat pharyngitis that are caused by beta-haemolytic streptococci.

\section{Acknowledgements}

We wish to thank the Director General of Health, Ministry of Health Malaysia for the permission to publish the findings (reference no. KKM.NIHSEC.800-4/4/1Jld.68(42)). We would like to thank doctors and nurses in the Department of Medical Microbiology, Department of Family Medicine at Universiti Putra Malaysia and the primary care clinics.

\section{Ethics of Study}

Ethics approval was granted by the Medical Research and Ethics Committee of the Ministry of Health Malaysia (NMRR15-2387-27757 (IIR)), and the Medical Research Ethics Committee of Universiti Putra Malaysia (UPMIINCPI/RMC/1.4.18.1 oKEUPM)/ FI). Written informed consents were obtained from all participants before data collection. 


\section{Conflicts of Interest}

None.

\section{Funds}

This study was supported by the Fundamental Research Grant Scheme from the Ministry of Education, Malaysia (Grant no: FRGS/1/2015/SKKo2/UPM/O3/1).

\section{Authors' Contributions}

Conception and design: ARM, NHS

Analysis and interpretation of the data: ARM, SZZ

Drafting of the article: ARM

Critical revision of the article for important intellectual content: AAR, SSG

Final approval of the article: NHS

Statistical expertise: SSG, RAH

Obtaining of funding: SZZ

Administrative, technical, or logistic support:

$\mathrm{RAH}$

Collection and assembly of data: AAR, SSG, MM, HSS

\section{Correspondence}

Dr Nurainul Hana Shamsuddin MBBS, MMed (Family Medicine)

(Universiti Malaya)

Department of Family Medicine,

Faculty of Medicine and Health Sciences, Universiti Putra Malaysia, 43400 UPM Serdang, Selangor, Malaysia.

Tel: +60397692538

Fax: +60389413802

E-mail: nurainul@upm.edu.my

\section{References}

1. Vos T, Allen C, Arora M, Barber RM, Bhutta ZA, Brown A, et al. Global, regional, and national incidence, prevalence, and years lived with disability for 310 diseases and injuries, 1990-2015: a systematic analysis for the global burden of disease study 2015. Lancet. 2016;388(10053):1545-1602. https://doi.org/ 10.1016/So140-6736(16)31678-6
2. Muthanna A, Salim HS, Hamat RA, Shamsuddin NH, Zakariah, SZ. Clinical screening tools to diagnose group A streptococcal pharyngotonsillitis in primary care clinics to improve prescribing habits. Malays $J$ Med Sci. 2018;25(6):6-21. https://doi.org/10.21315/ mjms2018.25.6.2

3. Hersh K, Fleming-Dutra KE, Shapiro DJ, Hyun DY, Hicks LA. Frequency of first-line antibiotic selection among US ambulatory care visits for otitis media, sinusitis, and pharyngitis. JAMA Intern Med. 2016;176(12):1870-1872. https://doi.org/10.1001/jamainternmed.2016.6622

4. Andersson DI, Hughes D, Kubicek-Sutherland JZ. Mechanisms and consequences of bacterial resistance to antimicrobial peptides. Drug Resist Updat. 2016;26(2016):43-57. https://doi.org/ 10.1016/j.drup.2016.04.002

5. Palla AH, Khan RA, Gilani AH, Marra F. Over prescription of antibiotics for adult pharyngitis is prevalent in developing countries but can be reduced using McIsaac modification of Centor scores: a cross-sectional study. BMC Pulm Med. 2012;12(1):70. https://doi.org/10.1186/1471 $-2466-12-70$

6. Teng CL, Leong KC, Aljunid SM, Cheah M. Antibiotic prescription in upper respiratory tract infections. Asia Pac Fam Med. 2004;3(1):38-45.

7. Teng CL. Antibiotic prescribing for upper respiratory tract infections in the Asia-Pacific region: A brief review. Malays Fam Physician. 2014;9(2):18-25.

8. Llor C, Bjerrum L. Antimicrobial resistance: risk associated with antibiotic overuse and initiatives to reduce the problem. Ther $A d v$ Drug Saf. 2014;5(6):229-241. https://doi.org/ 10.1177/2042098614554919

9. Ayukekbong JA, Ntemgwa M, Atabe AN. The threat of antimicrobial resistance in developing countries: causes and control strategies. Antimicrob Resist Infect Control. 2017;6(1):47. https://doi.org/10.1186/s13756-017-0208-x

10. DeMuri G, Sterkel AK, Kubica PA, Duster MN, Reed KD, Wald ER. Macrolide and clindamycin resistance in group A streptococci isolated from children with pharyngitis. Pediatr Infect Dis $J$. 2017;36(3):342-344. https://doi.org/10.1097/ INF.oooooooooooo1442 
11. Ray D, Saha S, Sinha S, Pal NK, Bhattacharya B. Molecular characterization and evaluation of the emerging antibiotic-resistant Streptococcus pyogenes from eastern India. BMC Infect Dis. 2016;16(1):753. https://doi.org/10.1186/s12879 $-016-2079-9$

12. Ministry of Health Malaysia. National Surveillance of Antibiotic Resistance. Kuala Lumpur: Institute for Medical Research; 2013. Available at: http://www.imr.gov.my.

13. Lemeshow S, Hosmer D, Klar W, Lwanga SK. Adequacy of sample size in health studies.1st ed. England: Wiley; 1990.

14. Treebupachatsakul P, Tiengrim S, Thamlikitkul V. Upper respiratory tract infection in Thai adults: prevalence and prediction of bacterial causes, and effectiveness of using clinical practice guidelines. J Med Assoc Thai. 2006;89(8):1178-1186.

15. Clinical and Laboratory Standards Institute. Performance standards for antimicrobial susceptibility testing. 26th ed. USA: Wayne Press; 2016.

16. Van Boeckel TP, Gandra S, Ashok A, Caudron Q, Grenfell BT, Levin SA, et al. Global antibiotic consumption 2000 to 2010: an analysis of national pharmaceutical sales data. Lancet Infect Dis. 2014;14(8):742-750. https://doi.org/10 .1016/S1473-3099(14)70780-7

17. Holloway KA, Ivanovska V, Wagner AK, VialleValentin C, Ross-Degnan D. Have we improved use of medicines in developing and transitional countries and do we know how to? Two decades of evidence. Trop Med Int Health. 2013;18(6):656664. https://doi.org/10.1111/tmi.12123

18. Fozi KM, Kamaliah MN. The effect of profiling report on antibiotic prescription for upper respiratory tract infection. Malays Fam Physician. 2013;8(2):26-31.

19. Ab Rahman N, Teng CL, Sivasampu S. Antibiotic prescribing in public and private practice: a crosssectional study in primary care clinics in Malaysia. BMC Infect Dis. 2016;16(1):208. https://doi .org/10.1186/s12879-016-1530-2
20. Hicks LA, Bartoces MG, Roberts RM, Suda KJ, Hunkler RJ, Taylor Jr TH, et al. US outpatient antibiotic prescribing variation according to geography, patient population, and provider specialty in 2011. Clin Infect Dis. 2015;60(9):1308-1316. https://doi.org/ $10.1093 / \mathrm{cid} / \mathrm{civo76}$

21. Tyrstrup M, van der Velden A, Engstrom S, Goderis G, Molstad S, Verheij T, et al. Antibiotic prescribing in relation to diagnoses and consultation rates in Belgium, the Netherlands and Sweden: use of European quality indicators. Scand J Prim Health Care. 2017;35(1):10-18. https://doi.org/10.108o/02813432.2017.1288680

22. Ministry of Health Malaysia. National Antibiotic Guideline. 2nd ed. Kuala Lumpur: Pharmaceutical Services Division; 2014. Available at: http://www .pharmacy.gov.my.

23. Mathan JJ, Ekart J, Mills C, Houlding A, Payinda G. Clinical management and patient persistence with antibiotic course in suspected group A streptococcal pharyngitis for primary prevention of rheumatic fever: the perspective from a New Zealand emergency department. $N Z \mathrm{Med} J$. 2017;130(1457):58-68.

24. Mazor O, Granek-Catarivas M, Giveon S. Common treatment for acute tonsillitis in the community. Harefuah. 2016;155(9):559-562.

25. Page-Sharp M, Coward J, Moore BR, Salman S, Marshall L, Davis TM, et al. A penicillin dried blood spot assay for use in patients receiving intramuscular benzathine penicillin $\mathrm{G}$ and other penicillin preparations to prevent rheumatic fever. Antimicrob Agents Chemother. 2017;61(8):17-25. https://doi.org/10.1128/ AAC.00252-17

26. Grijalva CG, Nuorti JP, Griffin MR. Antibiotic prescription rates for acute respiratory tract infections in US ambulatory settings. JAMA Journal. 2009;302(7):758-766. https://doi.org/ 10.1001/jama.2009.1163

27. Kunnamo A, Korppi M, Helminen M. Tonsillitis in children: unnecessary laboratory studies and antibiotic use. World J Pediatr. 2016;12(1):114117. https://doi.org/10.1007/s12519-015-0054-y 
28. Pelucchi C, Grigoryan L, Galeone C, Esposito $\mathrm{S}$, Huovinen $\mathrm{P}$, Little $\mathrm{P}$, et al. Guideline for the management of acute sore throat. Clin Microbiol Infect. 2012;18(1):1-28. https://doi.org/10.1111/ j.1469-0691.2012.03766.x

29. Abd El-Ghany SM, Abdelmaksoud AA, Saber SM, Abd El Hamid DH. Group A beta-hemolytic streptococcal pharyngitis and carriage rate among Egyptian children: a case-control study. Ann Saudi Med. 2015;35(5):377-382. https://doi.org/10.5144/0256-4947.2015.377

30. Dhanda V, Chaudhary P, Toor D, Kumar R, Chakraborti A. Antimicrobial susceptibility pattern of betahaemolytic group A, C and G streptococci isolated from North India. $J$ Med Microbiol. 2013;62(3):386-393. https://doi .org/10.1099/jmm.0.046672-0

31. Orrling A, Stjernquist-Desatnik A, Schalén C, Kamme C. Treatment failure in streptococcal pharyngotonsillitis: an attempt to identify penicillin tolerant Streptococcus pyogenes. Scand $J$ Infect Dis. 1996;28(2):143-7. http://dx.doi.org/10.3109/00365549609049065

32. Devi U, Borah PK, Mahanta J. The prevalence and antimicrobial susceptibility patterns of betahemolytic streptococci colonizing the throats of schoolchildren in Assam, India. $J$ Infect Dev Ctries. 2011;5(11):804-808. http://dx.doi.org/ $10.3855 /$ jidc. 1465

33. Jachna-Sawicka K, Pietrzak A, Bogiel T, Gospodarek E. Antibiotic sensitivity of betahemolytic streptococci isolated from throat swabs and purulent material. Med Dosw Mikrobiol. 2010;62(4):309-17.

34. Zafar A, Hasan R, Nizamuddin S, Mahmood N, Mukhtar S, Ali F, et al. Antibiotic susceptibility in Streptococcus pneumoniae, Haemophilus influenzae and Streptococcus pyogenes in Pakistan: a review of results from the Survey of Antibiotic Resistance (SOAR) 2002-15. $J$ Antimicrob Chemother. 2016;71(1):103-109. https://doi.org/10.1093/jac/dkw076

35. Traub WH, Leonhard B. Comparative susceptibility of clinical group A, B, C, F, and $\mathrm{G}$ beta-hemolytic streptococcal isolates to 24 antimicrobial drugs. Chemotherapy. 1997;43(1):10-20.
36. Al-Charrakh AH, Al-Khafaji JKT, Al-Rubaye RHS. Prevalence of $\beta$-hemolytic groups $\mathrm{C}$ and $\mathrm{F}$ streptococci in patients with acute pharyngitis. NAm J Med Sci. 2011;3(3):129-136.

37. Donnelly JP, Baddley JW, Wang HE. Antibiotic utilization for acute respiratory tract infections in U.S. emergency departments. Antimicrob Agents Chemother. 2014;58(30):1451-1457. https://doi.org/10.4297/najms.2011.3129

38. Calle-Miguel L, Perez-Méndez C, MinguelMartínez M, Lombrana-Álvarez E， GarcíaGarcía E, Solis-Sánchez G. Resistance rates and phenotypic characterization of Streptococcus pyogenes in a paediatric population in Northern Spain (2005-2015). Rev Esp Quimioter. 2017;30(2):90-95.

39. Petković H, Lukezič T, Susković J. Biosynthesis of oxytetracycline by Streptomyces rimosus: past, present and future directions in the development of tetracycline antibiotics. Food Technol Biotechnol. 2017;55(1):3-13. https://doi.org/10.17113/ftb.55.01.17.4617

40. Hraoui M, Boubaker IBB, Rachdi M, Slim A, Redjeb SB. Macrolide and tetracycline resistance in clinical strains of Streptococcus agalactiae isolated in Tunisia. $J$ Med Microbiol. 2012;61(8):1109-1113. https://doi.org/10.1099/ jmm.0.037853-0

41. Tantivitayakul P, Lapirattanakul J, Vichayanrat T, Muadchiengka T. Antibiotic resistance patterns and related mobile genetic elements of pneumococci and $\beta$-hemolytic streptococci in Thai healthy children. Indian $J$ Microbiol. 2016;56(4):417-425. https://doi.org/10.1007/ s12088-016-0607-3

42. Lin FYC, Azimi PH, Weisman LE, Philips JB, Regan J, Clark P, et al. Antibiotic susceptibility profiles for group B streptococci isolated from Neonates, 1995-1998. Clin Infect Dis. 2000;31(1):76-79. https://doi.org/10.1086/ 313936

43. Mathur P, Bhardwaj N, Mathur K, Behera B, Gupta G, Kapil A, et al. Clinical and molecular epidemiology of beta-hemolytic streptococcal infections in India. $J$ Infect Dev. 2014;8(3):297303. https://doi.org/10.3855/jidc.3216 
44. Allen K, Farah CS. Screening and referral of oral mucosal pathology: A check-up of Australian dentists. Aust Dent J. 2015;60(1):52-58. https://doi.org/10.1111/adj.12261

45. Orden B, Martínez R, López de los Mozos A, Franco A. Antibiotic resistance to erythromycin, clindamycin and tetracycline of 573 strains of Streptococcus pyogenes (1992-1994). Enferm Infecc Microbiol Clin. 1996;14(2):86-89.
46. Strömberg A, Schwan A, Cars O. Throat carrier rates of beta-hemolytic streptococci among healthy adults and children. Scand $J$ Infect Dis. 1988;20(4):411-417. https://doi.org/10.3109/ o0365548809032477

47. Fujita K, Murono K, Yoshikawa M, Murai T. Decline of erythromycin resistance of group A streptococci in Japan. Pediatr Infect Dis $J$. 1994;13(1):1075-1078. https://doi.org/10.1097/ o0o06454-199412000-00001 